Review

\title{
Palmitoylethanolamide for Neurological Disorders
}

Jordi Faig-Martí *

Orthopaedic Surgery Department, Hospital de Sant Rafael (Barcelona), Pg. Vall d'Hebron 107-117, 08035 Barcelona, Catalonia, Spain; E-Mail: jfaigm.hsrafael@hospitalarias.es

* Correspondence: Jordi Faig-Martí; E-Mail: jfaigm.hsrafael@hospitalarias.es

Academic Editor: Ping K. Yip

Special Issue: Neuroprotection, Neuroregeneration and Neuroplasticity

OBM Neurobiology

2020 , volume 4 , issue 4

doi:10.21926/obm.neurobiol.2004076
Received: October 04, 2020

Accepted: December 10, 2020

Published: December 30, 2020

\begin{abstract}
Neurological tissue along with the cartilage remains one of the tissues that escapes human efforts of regeneration after injury. The human body, after an injury, can repair its tissues only to a certain extent that can help in recovering the function of organs. However, this is not the case in some organs, such as the brain and spinal cord. For a long time, basic medical science has been investigating the regeneration process that helps the human body, which is mainly through the pharmacological agents, proteins/other molecules acting as cellular transmitters or by the scaffolding of tissues that allows the cells to grow in them and also by other techniques such as electrical currents or electromagnetic waves.
\end{abstract}

\section{Keywords}

Palmitoylethanolamide; neurological disorders

Neuroinflammation is characterized by the infiltration of the immune system cells and the activation of inflammatory mediators. It is one of the components of neural damage, which, if eliminated, could be a key to neurological recovery. The inflammatory cascade, with the activation

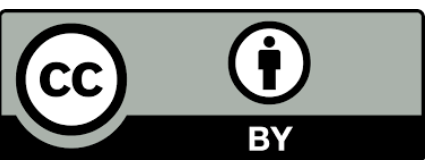

(C) 2020 by the author. This is an open access article distributed under the conditions of the Creative Commons by Attribution License, which permits unrestricted use, distribution, and reproduction in any medium or format, provided the original work is correctly cited. 
of mast cells and glial cells, along with the release of inflammatory agents, creates an unfavorable environment for tissue recovery. Thus, if the tissues could be "cleaned from inflammation", a favorable environment could be created for tissue regeneration. In this regard, several pharmacological agents and chemical mediators have been investigated. The family of ALIAmides (Autacoid Local Injury Antagonist Amides), particularly palmitoylethanolamide (PEA), emerged as mediators of inflammation in the pursuit of agents that heal the neurological tissues and play a role in the improvement of neurological conditions. This family of endogenous molecules plays a role in modifying physiological processes within the physiological pathways, hence, this approach is less prone to side effects in a clinical setting [1, 2].

PEA is an endogenous fatty acid amide proved to reduce inflammation in several experimental models [3-5], hence it is used clinically in reducing pain [6-8]. An experimental study in rats showed a positive effect of PEA on the neuroinflammation of the sciatic nerve that occurred due to compression [9]. Its effect is mediated by peroxisome proliferator-activated receptor-(PPAR-) $\alpha$, which is a nuclear receptor that plays a role in controlling the inflammatory responses [10]. In this study, the rats showed both clinical and histological improvement, along with a reduction in macrophage infiltration.

Some years ago, we conducted a randomized double-blinded clinical study to evaluate the effects of PEA in carpal tunnel syndrome (CTS) [11]. At that time, the pharmaceutical company that commercialized PEA recommended its dosage as $600 \mathrm{mg}$ per day for treating CTS. Although the electrodiagnostic testing showed no improvement with this treatment, improvements were seen in some items only in the questionnaire. The functional status scale (FFS) and symptom severity scale (SSS) of Levine's questionnaire showed a statistically significant improvement with the values of $11.3 \%$ in the former and $13.1 \%$ in the latter. Our results showed no clear benefits of this approach in treating the condition. However, the dosage was also lower than the ones reported in the other studies. A study with a $1200 \mathrm{mg}$ dosage per day of PEA indicated a clinical improvement in CTS [12] even though the case was associated with diabetes. Therefore, one of our conclusions recommends a higher dose of PEA in further clinical studies to determine its usefulness in the treatment of carpal tunnel syndrome.

Most of the studies that used PEA were performed to treat peripheral nerve conditions, but this molecule was also found in brain disturbances [13]. Since we know PEA's role as a modulator in neuroinflammation, we may also consider its effects in several brain pathologies where inflammation was detected. However, the first subject to be addressed was to know if the exogenous administration of PEA could reach the brain as it could reach the peripheral nerves. Once this was ascertained, the clinical effect of PEA in brain disturbances could also be studied. PEA is thought to penetrate the blood-brain barrier in small amounts [14], which is attributed to PEA being poorly water-soluble. This reduced its digestive absorption and bioavailability, or also its degradation by hydrolases. Therefore, delivering this molecule to its target site in the brain cells becomes the first challenge.

The different formulations available in theory have different degrees of digestive absorption that add to the difficulty of assessing its bioavailability. Reducing the particle size of the formulation with this compound can increase the digestive absorption of PEA, where micronized and ultra-micronized PEA can improve its diffusion in the body tissues [15].

The nuclear receptor PPAR- $\alpha$, targeted by the PEA, can also interact with other molecules such as fenofibrate and $\mathrm{W} y-14643$ to protect against cerebral injury during stroke in mice models [16, 
17]. PEA also targets other receptors such as GPR55, which is found in the brain cells, and may play a role in reducing inflammation [18] by reducing the pro-inflammatory enzyme expression while increasing the neurosteroid synthesis [19]. Also, the combination of other molecules, such as antioxidant flavonoids, can act synergistically with PEA to achieve therapeutic effects [15]. A reduction of inflammation in the neurological tissue could decrease the effects of an injury (for example, ischaemic or traumatic injury in the brain) and facilitate a favorable clinical outcome.

The promising results of PEA in the treatment of peripheral nerve neuroinflammation makes us believe that it could also be useful in brain neuroinflammation. Experimental studies in rats have shown the effects of PEA in behavioral dysfunction [20]. Some clinical studies have also suggested that PEA can be used in amyotrophic lateral sclerosis (ALS) [21] and ischaemic stroke [22], but our knowledge remains limited in this field. Hence, extensive studies are further required to define the role of PEA in the treatment of neurological disorders.

\section{Author Contributions}

Dr. Jordi Faig-Martí did all work.

\section{Competing Interests}

The author has declared that no competing interests exist.

\section{References}

1. Hesselink, JM. Fundamentals of and critical issues in lipid autacoid Medicine: A review. Pain Ther. 2017; 6: 153-164.

2. Penson PE. Autonomic \& autacoid pharmacology: Past, present and future. Auton Autacoid Pharmacol. 2015; 35: 45.

3. Mazzari S, Canella R, Petrelli L, Marcolongo G, Leon A. N-(2-hydroxyethyl) hexadecanamide is orally active in reducing edema formation and inflammatory hyperalgesia by down-modulating mast cell activation. Eur J Pharmacol. 1996; 300: 227-236.

4. Costa B, Conti S, Giagnoni G, Colleoni M. Therapeutic effect of the endogenous fatty acid amide, palmitoylethanolamide, in rat acute inflammation: Inhibition of nitric oxide and cyclooxygenase systems. Br J Pharmacol. 2002; 137: 413-420.

5. Re G, Barbero R, Miolo A, Di Marzo V. Palmitoylethanolamide, endocannabinoids and related cannabimimetic compounds in protection against tissue inflammation and pain: Potential use in companion animals. Vet J. 2007; 173: 21-30.

6. Conigliaro R, Drago V, Foster PS, Schievano C, Marzo VDI. Use of palmitoylethanolamide in the entrapment neuropathy of the median in the wrist. Minerva Med. 2011; 102: 141-147.

7. Jaggar SI, Hasnie FS, Sellaturay S, Rice AS. The anti-hyperalgesic actions of the cannabinoid anandamide and the putative CB2 receptor agonist palmitoylethanolamide in visceral and somatic inflammatory pain. Pain. 1998; 76: 189-199.

8. Calignano A, La Rana G, Giuffrida A, Piomelli D. Control of pain initiation by endogenous cannabinoids. Nature. 1998; 394: 277-281

9. Di Cesare Mannelli L, D'Agostino G, Pacini A, Russo R, Zanardelli M, Ghelardini C, Calignano A. Palmitoylethanolamide is a disease-modifying agent in peripheral neuropathy: Pain relief and 
neuroprotection share a ppar-alpha-mediated mechanism. Mediators Inflamm. 2013; 2013: 328797.

10. Glass CK, Ogawa S. Combinatorial roles of nuclear receptors in inflammation and immunity. Nat Rev Immunol. 2006; 6: 44-55.

11. Faig-Martí J, Martínez-Catassús A. Use of palmitoylethanolamide in carpal tunnel syndrome: A prospective randomized study. J Orthop Traumatol 2017; 18: 451-455.

12. Assini A, Laricchia D, Pizzo R, Pandolfini L, Belletti M, Colucci M, et al. The carpal tunnel syndrome in diabetes: Clinical and electrophysiological improvement after treatment with palmitoylethanolamide. Eur J Neurol. 2010; 17: 295.

13. Cordaro M, Cuzzocrea S, Crupi R. An update of palmitoylethanolamide and luteolin effects in preclinical and clinical studies of neuroinflammatory events. Antioxidants. 2020; 9: 216.

14. Artamonov M, Zhukov O, Shuba I, Storozhuk L, Khmel T, Klimashevsky V, et al. Incorporation of labelled $\mathrm{N}$-acylethanolamine (NAE) into rat brain regions in vivo and adaptive properties of saturated NAE under x-ray irradiation. Ukr Biokhim Zh. 1999; 77: 51-62.

15. Petrosino S, Di Marzo V. The pharmacology of palmitoylethanolamide and first data on the therapeutic efficacy of some of its new formulations. Br J Pharmacol. 2017; 174: 1349-1365.

16. Inoue H, Jiang XF, Katayama T, Osada S, Umesono K, Namura S. Brain protection by resveratrol and fenofibrate against stroke requires peroxisome proliferator-activated receptor $\alpha$ in mice. Neurosci Lett. 2003; 352: 203-206.

17. Deplanque D, Gelé P, Pétrault O, Six I, Furman C, Bouly M, et al. Peroxisome proliferatoractivated receptor- $\alpha$ activation as a mechanism of preventive neuroprotection induced by chronic fenofibrate treatment. J Neurosci. 2003; 23: 6264-6271.

18. Yang H, Zhou J, Lehmann C. GPR55 - a putative "type 3 " cannabinoid receptor in inflammation. J Basic Clin Physiol Pharmacol. 2016; 27: 297-302

19. Mattace Raso G, Russo R, Calignano A, Meli R. Palmitoylethanolamide in CNS health and disease. Pharmacol Res. 2014; 86: 32-41.

20. Guida F, Boccella S, lannotta M, De Gregorio D, Giordano C, Belardo C, et al. Palmitoylethanolamide reduces neuropsychiatric behaviors by restoring cortical electrophysiological activity in a mouse model of mild traumatic brain injury. Front Pharmacol. 2017; 8: 95.

21. Clemente S. Amyotrophic lateral sclerosis treatment with ultramicronized palmitoylethanolamide: A case report. CNS Neurol Disord Drug Targets. 2012; 11: 933-936.

22. Caltagirone C, Cisari C, Schievano C, Di Paola R, Cordaro M, Bruschetta G, et al. Coultramicronized palmitoylethanolamide/luteolin in the treatment of cerebral ischemia: From rodent to man. Transl Stroke Res. 2016; 7: 54-69. 


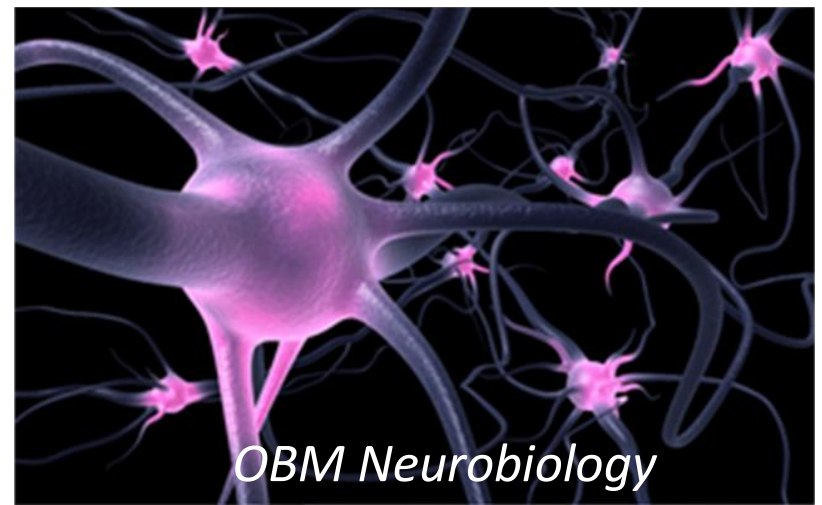

Enjoy OBM Neurobiology by:

1. Submitting a manuscript

2. Joining volunteer reviewer bank

3. Joining Editorial Board

4. Guest editing a special issue

For more details, please visit:

http://www.lidsen.com/journals/neurobiology 